\title{
Structural and Magnetic Properties of Nanoparticles of NiCuZn Ferrite Prepared by the Self-Combustion Method
}

\author{
S.E. Jacobo ${ }^{1, ~ a ~, J . C . ~ A p h e s t e g u y ~}{ }^{1, b}$ N.N. Shegoleva ${ }^{2, c}$ and \\ G.V. Kurlyandskaya ${ }^{3,4, d}$ \\ ${ }^{1}$ LAFMACEL, Fac. de Ingeniería, Univ. de Bs As, P. Colón 850 (1063), Buenos Aires, Argentina \\ ${ }^{2}$ Institute of Metal Physics UD RAS, S. Kovalevskoi str. 18, 620990, Ekaterinburg, Russia \\ ${ }^{3}$ Ural State University A.M. Gorky, Lenin 51, 620083, Ekaterinburg, Russia \\ ${ }^{4}$ Dep. of Electricity and Electronics, Univ. of The Basque Country UPV-EHU, Leioa, 48940, Spain \\ asjacobo@fi.uba.ar, ${ }^{b}$ caphestegu@fi.uba.ar, 'vlasova@imp.uran.ru, ${ }^{\text {d }}$ galina@we.lc.ehu.es
}

Keywords: self-combustion method, X-ray diffraction, magnetic nanoparticles, soft magnetic ferrites.

\begin{abstract}
NiCuZn ferrites were prepared by the sol-gel self-combustion method. Nanosized, homogeneous and highly reactive powders were obtained at relatively low temperatures. In present work the variations of structural, magnetic, and microwave properties of $\mathrm{NiCuZn}$ ferrite nanoparticles were studied as a function of the annealing temperature. The analysis of XRD patterns showed that only the spinel phase is present. Cell parameters slightly vary with thermal treatment while a crystalline size increases. Magnetic nanoparticles were mixed with an epoxy resin for reflectivity studies with a microwave vector network analyzer using the microwave-guide method in the range of 7.5 to $13.5 \mathrm{GHz}$. Static saturation magnetization value (measured by SQUID) and microwave absorption show clear dependence on the annealing temperature/particle size and the absorption maximum moves towards the higher frequencies with an increase in the average size of the particles.
\end{abstract}

\section{Introduction}

Spinel ferrites are commercially important materials because of their excellent magnetic and electrical properties [1]. They have been utilized as radar absorbing materials (RAM) in various forms for many years due to their large magnetic losses and large resistivity. However, in the microwave region, the applications of spinel ferrites are limited by the lower end of microwave frequencies (1-3 GHz) compared with hexaferrites [2]. The effect of $\mathrm{Cu}$ substitution on the magnetic and electrical properties of NiZn ferrite has been reported by Nakamura and Shroti [3-4]. Magnetic properties of ferrites, including the temperature dependence of relative initial permeability, depend heavily on their compositions and microstructures [5-9]. Although the coprecipitation and the sol-gel processes are the most popular, they have some disadvantages since they are highly $\mathrm{pH}$-sensitive and require special attention for complex systems such as $\mathrm{NiCuZn}$. The sol-gel self-combustion method has much simple processing steps. It has the advantages of using inexpensive precursors [10]. In present work the nanosized, homogeneous and highly reactive powders were obtained at relatively low temperatures in order to investigate the influence of the annealing temperature on their structural, magnetic properties and microwave reflecting losses $\left(R_{\mathrm{L}}\right)$.

\section{Experimental}

In the present work, the substituted $\mathrm{Ni}_{0.35} \mathrm{Cu}_{0.15} \quad \mathrm{Zn}_{0.5} \mathrm{Fe}_{2} \mathrm{O}_{4}$ ferrites were prepared by the selfcombustion method [6]. Different proportions of iron nitrates, nickel, cooper, and zinc oxalates were weighed according to the required stoichiometric proportion and diluted in water (in all 
preparations, $[\mathrm{Fe}(\mathrm{III})]+[\mathrm{Ni}(\mathrm{II})]+[\mathrm{Zn}(\mathrm{II})]+[\mathrm{Cu}(\mathrm{II})]=1 \mathrm{M})$. A $3 \mathrm{M}$ citric acid solution $(50 \mathrm{~mL})$ was added to each metal solution $(50 \mathrm{~mL})$ and heated at $40^{\circ} \mathrm{C}$ for approximately $30 \mathrm{~min}$ with continuous stirring. The final mixture was slowly evaporated until a highly viscous gel was formed. The resulting gel was heated at $T \sim 200^{\circ} \mathrm{C}$, when it ignited in a self-propagated process. The final residue (ash) was calcined at $550^{\circ} \mathrm{C}, 800^{\circ} \mathrm{C}$ and $1100^{\circ} \mathrm{C}$ for two hours. The samples nominations are shown in Table I.

Table 1 Nominations, structural, and room temperature magnetic characteristics of the samples

\begin{tabular}{|l|l|l|l|l|l|}
\hline Samples & $\mathrm{Ni}_{0.5-\mathrm{x}} \mathrm{Cu}_{\mathrm{x}} \mathrm{Zn}_{0.5} \mathrm{Fe}_{2} \mathrm{O}_{4}$ & cell parameter $[\AA]$ & crystalline size $[\mathrm{nm}]$ & $\mathrm{M}_{\mathrm{s}}[\mathrm{emu} / \mathrm{g}]$ & $\mathrm{H}_{\mathrm{c}}[\mathrm{Oe}]$ \\
\hline M-I & as-prepared (ash) & $8.3996 \pm 0.001$ & 12.5 & 37 & 100 \\
\hline $\mathrm{M}-\mathrm{II}$ & $550^{\circ} \mathrm{C}$ & $8.4000 \pm 0.001$ & 32.2 & 65 & 27 \\
\hline $\mathrm{M}-\mathrm{III}$ & $800^{\circ} \mathrm{C}$ & $8.4121 \pm 0.001$ & 71 & 75 & 21.9 \\
\hline $\mathrm{M}-\mathrm{IV}$ & $1100^{\circ} \mathrm{C}$ & $8.4052 \pm 0.001$ & 116 & 84 & 11.6 \\
\hline
\end{tabular}

In order to characterize the auto-combustion process, the original gel and the ash prepared powders (M-I) were heated in a Shimadzu TGA-51 equipment at a heating rate of $10^{\circ} \mathrm{C} \mathrm{min}-1$ in air atmosphere. Nanoparticles were characterized by the X-ray diffraction method using a Bruker D8 Advance diffractometer equipped with a $\mathrm{Cu}$ tube, $\mathrm{Ge}$ (111) incident beam monochromator $(\lambda=1.5406 \AA)$ and a Sol-X energy dispersive detector. The corresponding intensities were measured for $2 \theta$ angles from 15 to $90^{\circ}$ with a step $0.02^{\circ}$ and in the standard Bragg-Brentano geometry. Average crystalline size of nanoparticles was calculated for the strongest diffraction peak in the (311) plane from the line broadening using the Scherer equation corrected for instrumental broadening [11] and given by: $D=0.89 \lambda / \xi \cos \theta$, where $D$ is the crystalline size, $\lambda$ is the wavelength of the radiation used, $\xi$ is the full width at half maximum after making the correction due to instrumental broadening and $\theta$ is the scattering angle. Cell parameters for the ferrite phase were calculated from XRD patterns using the cell powder programme. XRD diffraction data were fitted using the FULLPROF program included in WinPLOTR [12-13]. At the profile refinement the unit cell parameters, peak shape (pseudo-Voigt), a background, systematic $2 \theta$ shift, an overall isotropic displacement, $U, V, W$ half-width parameters for the profile function and asymmetry parameters were calculated. Transmission electron microscopy (TEM) was performed after sedimenting of the particles on carbon-coated copper grids.

Magnetic measurements of $\mathrm{Ni}_{0.35} \mathrm{Cu}_{0.15} \mathrm{Zn}_{0.5} \mathrm{Fe}_{2} \mathrm{O}_{4}$ nanoparticles were performed at room and cryogenic temperatures using superconducting quantum interface device SQUID. The nanoparticles were placed into a gelatin capsule under a small pressure (in order to avoid their movement in a magnetic field). Hysteresis loops were measured at temperatures of 5, 10, 50150 and $300 \mathrm{~K}$. Zero field cooling (ZFC) and field cooling (FC) curves were obtained for the field values selected on the basis of the analysis of the $M(H)$ curves.

In order to explore microwave-absorbing properties in the X-band, magnetic nanoparticles of each sample were mixed with an epoxy resin to be converted to a microwave-absorbing composite and microwave behavior was analyzed from 7.5 to $13.5 \mathrm{GHz}$. Reflectivity measurements were carried out using the wave-guide method. Samples were prepared in a rectangular shape of size $12.4 \mathrm{~mm} \times 24.2 \mathrm{~mm}$ to fit in rectangular wave-guide of the X-band. All composite samples had the same composition $(17 / 83 \mathrm{wt} \%)$ and the same thickness $(2.0 \mathrm{~mm})$. The wave-guide fitted with sample was backed by a metal short for reflection loss using HP network analyzer (model ANRITSU 37247 D, $40 \mathrm{MHz}-20 \mathrm{GHz}$ ). 


\section{Results and Discussion}

Figure 1 shows $T G$ curves of the obtained gel in order to clarify the chemical reactions of the $\mathrm{Ni}_{0.35} \mathrm{Cu}_{0.15} \mathrm{Zn}_{0.5} \mathrm{Fe}_{2} \mathrm{O}_{4}$ precursors during the pyrolysis process. It was found that there were three weight loss processes that occurred at $160-166^{\circ} \mathrm{C}, 166-233^{\circ} \mathrm{C}, 242-322^{\circ} \mathrm{C}$ with a total weight loss of $63.3 \%$. The first weight loss was about $50.0 \%$ of total weight, corresponding to the decomposition of the gel by oxidation reactions of organic compounds (citrates and acetates) and the loss of absorbed water in the precursor. The second weight loss was about $5.5 \%$ of total weight, corresponding to the decomposition of nitrate. The third weight loss was about $7.8 \%$ and probably may arise from the decomposition of $\mathrm{Cu}-\mathrm{Ni}-\mathrm{Zn}-\mathrm{Fe}$ compounds into metal oxides.

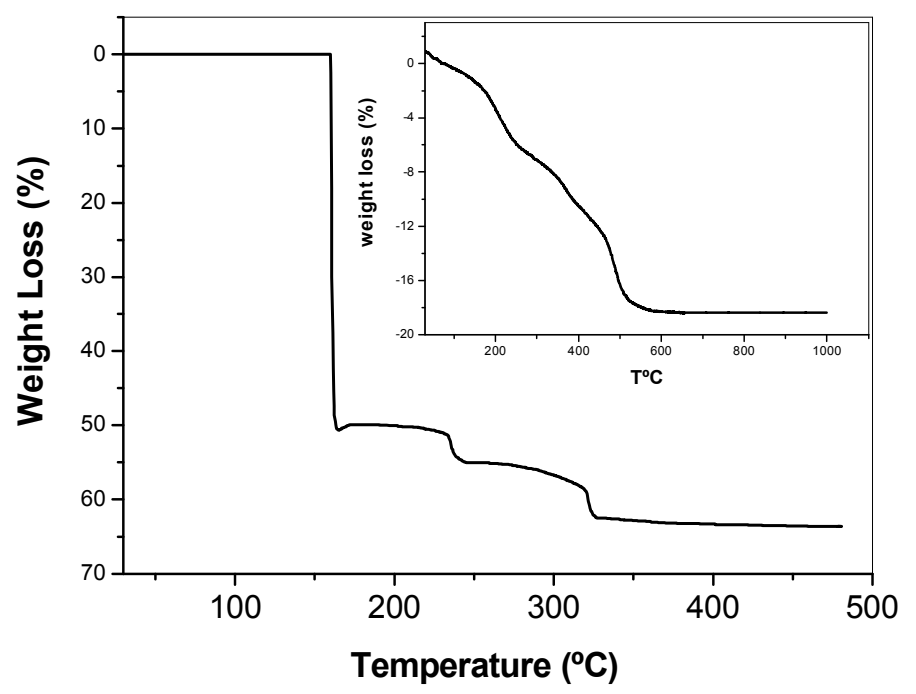

Fig. 1. $T G$ curves of the dried nitrate-citrate gel powder.

The inset: The ash prepared powders (M-I) heated from room temperature to $1000^{\circ} \mathrm{C}$

It is obvious that above $350^{\circ} \mathrm{C}$ the weight was almost constant, indicating that the final decomposed products are ferrites. The inset shows that the ash prepared powders presents a weight loss of $18 \%$ up to $550^{\circ} \mathrm{C}$. These results suggest that sample M-I retain some organic precursor compounds. These considerations can be related to the DRX analysis. The main result obtained from XRD studies (Figs.2 and 3) is that the obtained materials are indeed uniform single cubic fcc (Fd3m) phase spinels having a typical NiCuZnFe phases: [220], [311], [222], [400], [422], [511] and [400].

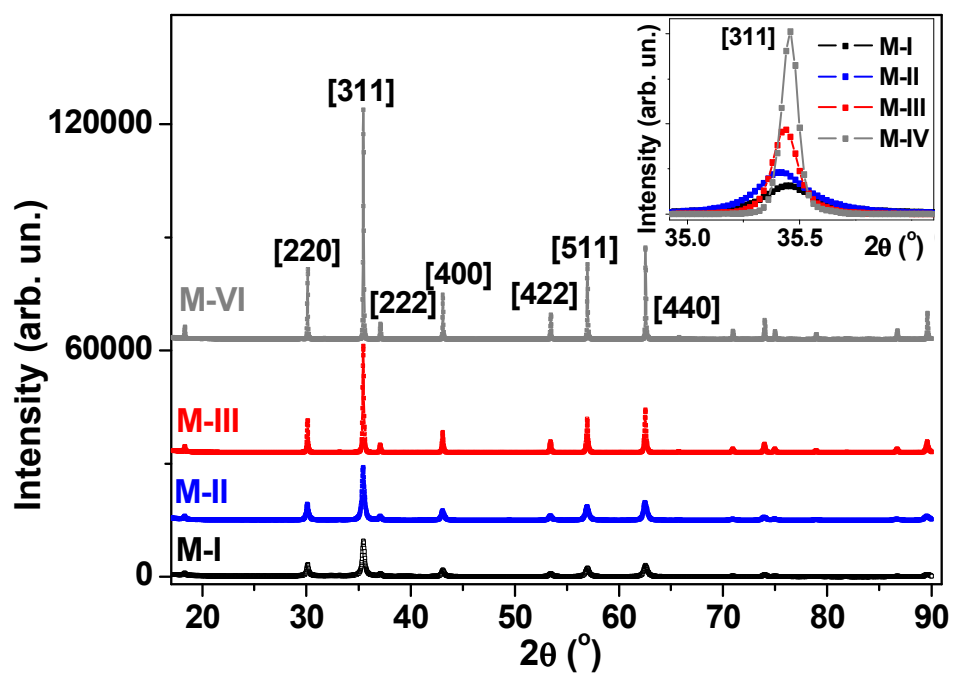

Fig. 2. XRD patterns of $\mathrm{Ni}_{0.5-\mathrm{x}} \mathrm{Cu}_{\mathrm{x}}$ $\mathrm{Zn}_{0.5} \mathrm{Fe}_{2} \mathrm{O}_{4}$ nanoparticles in the initial state and annealed at different temperatures of post-preparation treatments. Identified Bragg reflections are typical spinel ferrite phases indicated in brackets. The inset shows most intensive (311) diffraction peaks in more detail.

Similar structure was earlier reported for $\mathrm{Ni}_{0.35} \mathrm{Cu}_{0.11} \mathrm{Zn}_{0.57} \mathrm{Fe}_{1.97} \mathrm{O}_{4}$ ferrite nanoparticles prepared by sol-gel self-combustion method in different atmospheres [14]. According to the XRD studies the cell parameters slightly vary with thermal treatment while a crystalline size increases with an increase of the temperature of post preparation treatment from about 12 to $115 \mathrm{~nm}$. The diffraction peaks from M-I and M-II samples of a small size were broader than the expected from small size 
nanoparticles [15]. L. Yu et al. [14] have shown that a complete spinel construction of nanocrystalline $\mathrm{NiCuZn}$ ferrite may form at the temperature of about $480^{\circ} \mathrm{C}$. Therefore the structure of the M-I sample was studied in more details. Fine features of XRD spectra indicate that although the main volume of the M-I samples was typical $\mathrm{NiCuZnFe}$ ferrite phase, there was a possibility for the as-prepared nanoparticles to have imperfections, local deviations from cubic fcc spinel, accumulation of stresses or the presence of elemental $\mathrm{Zn}$ segregations (for volume amount below $1 \%)$.

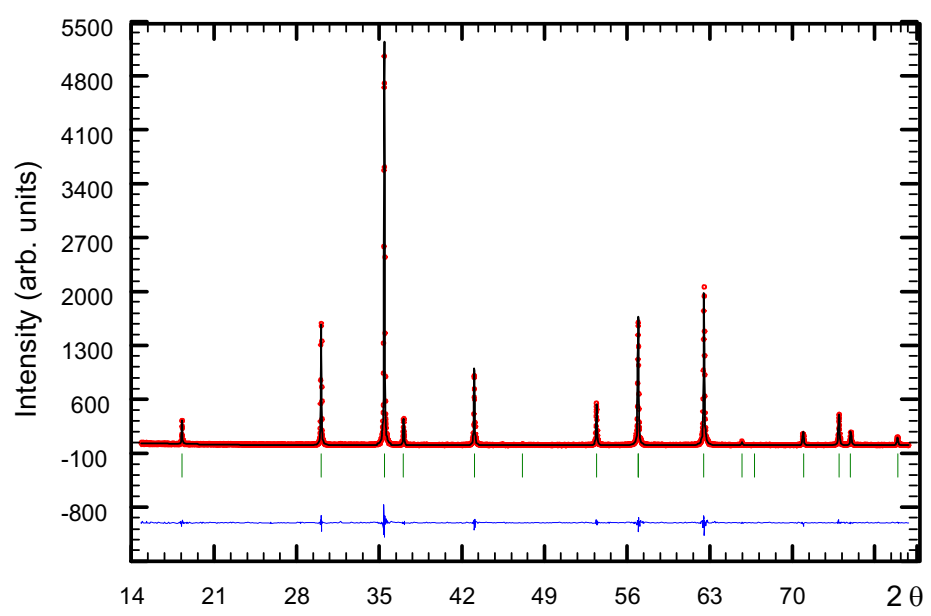

Fig. 3. XRD patterns of $\mathrm{Ni}_{0.5-\mathrm{x}} \mathrm{Cu}_{\mathrm{x}}$ $\mathrm{Zn}_{0.5} \mathrm{Fe}_{2} \mathrm{O}_{4} \quad$ M-IV nanoparticles annealed at $1100^{\circ} \mathrm{C}$. Comparison of observed (circles) and calculated (solid line) intensities. The difference pattern is shown below. The vertical bars in the middle position indicate the positions of Bragg reflections.

It can clearly be seen from TEM images in Fig.4, that there are areas with increased dislocation density filling the grain boundaries for the sample M-IV. For copper-substituted NiZn ferrite obtained by the coprecipitation process structural peculiarity near the grain boundaries were proved to be $\mathrm{Cu}$-rich phase [16]. The presence of $\mathrm{Cu}^{+}$ions near the grain boundaries causes a decrease of the lattice parameters of the sample M-IV sintered at $1100^{\circ} \mathrm{C}$ in Table 1 . The grain size continues to rise from about $12 \mathrm{~nm}$ to $115 \mathrm{~nm}$ while increasing the sintering temperature that is also much larger than that of NiZn ferrite prepared through the same fabrication process $[5,6,17]$. In this case a liquid phase sintering takes place when the material transfer is much faster than in solid phase. This can explain the spectacular increase of the grain size.

Figure 5 shows two examples of the field dependence of the magnetization for M-I and M-II types of $\mathrm{Ni}_{0.35} \mathrm{Cu}_{0.15} \mathrm{Zn}_{0.5} \mathrm{Fe}_{2} \mathrm{O}_{4}$ nanoparticles (see also Table 2). The most important result is that for all the samples and temperatures the non-zero coercivity was observed indicating the presence of the strong ferromagnetic contribution. The same conclusion was made from the analysis of ZFC-FC curves. As temperature increases saturation magnetization (measured at $1 \mathrm{~T}$ ) increases from 37 $\mathrm{emu} / \mathrm{g}$ to $84 \mathrm{emu} / \mathrm{g}$.

Figure 6 shows zero field cooling and field cooling curves for the following values of an external field $H$ : $100 \mathrm{Oe}, 200 \mathrm{Oe}$ and $1 \mathrm{kOe}$. As the temperature decreased from 340 to $5 \mathrm{~K}$ a certain increase of the magnetization was observed (especially well seen for $H=1$ kOe curves). An increase of the $M_{\mathrm{s}}$ with the increase of the post preparation treatment temperature is not surprising. The first explanation comes from the detailed analysis of the X-ray data, namely, the existence of the imperfections, local deviations from cubic fec spinel or accumulation of stresses in the structure of the M-I sample. The second reason is a small size of nanoparticles with very high surface-to-volume ratio that decreases with increase of an average grain size. There are many reports on similar decrease of the saturation magnetization for magnetic nanoparticles with a decrease of their average size $[18,19]$. The shapes of the ZFC-FC curves clearly indicate that the superparamagnetic phase (if any) is not dominant for all types of the nanoparticles: there is no sharp peak in the ZFC branch of the curve, which is usually associated with the mean blocking temperature of superparamagnetic nanoparticles. Figure 7 shows temperature dependence of the saturation magnetization, the coercive forces and the dependence of the room temperature coercivity on the average size of nanoparticles, which can be described by empiric low: $H_{\mathrm{c}} \sim 1 / D$. The highest coercivity appears in the M-I sample. It can also be explained by the existence of the imperfections, local deviations from cubic fcc 
structure or accumulation of stresses. In fact, complex behavior represented by ZFC-FC curves is a consequence of non-zero coercivity of the nanoparticles. It can be understood taking into account the temperature dependence of the $H_{\mathrm{c}}$
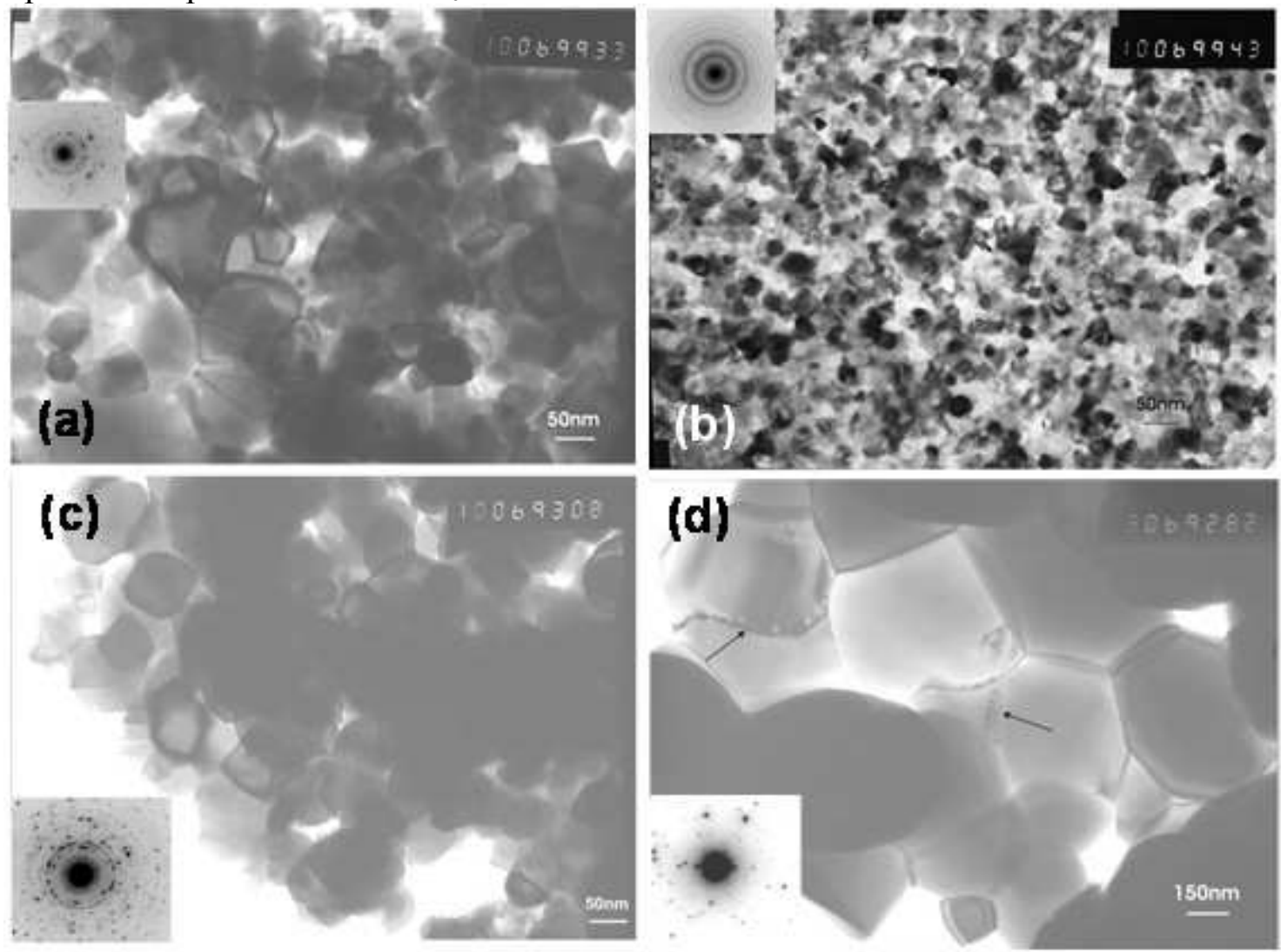

Fig. 4. TEM micrographs of the $\mathrm{Ni}_{0.35} \mathrm{Cu}_{0.15} \mathrm{Zn}_{0.5} \mathrm{Fe}_{2} \mathrm{O}_{4}$ nanoparticles: (a) M-I, (b) M-II, (c) M-III and (d) M-IV, respectively (arrows show the increased dislocations areas near the grain boundary).
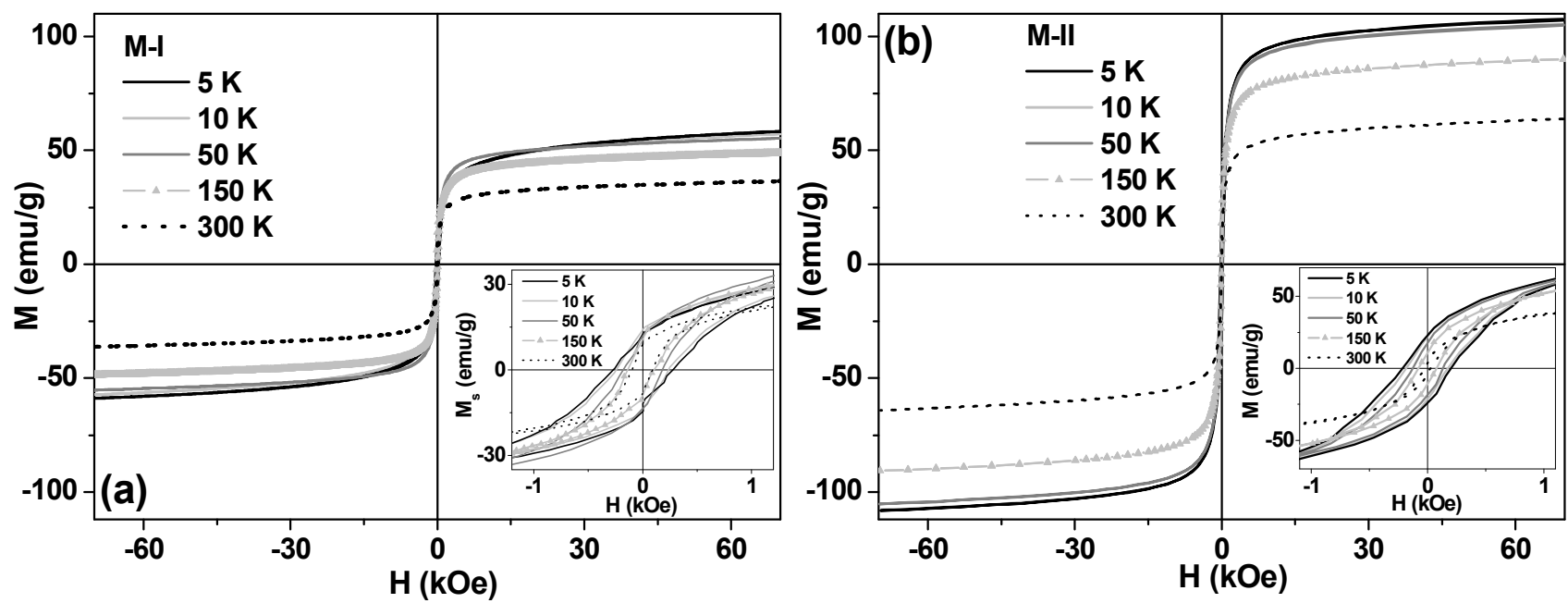

Fig. 5. Magnetization hysteresis loops measured at selected temperatures for the M-I (a) and M-II (b) $\mathrm{Ni}_{0.35} \mathrm{Cu}_{0.15} \mathrm{Zn}_{0.5} \mathrm{Fe}_{2} \mathrm{O}_{4}$ nanoparticles. The insets shows the details of the $\mathrm{M}(\mathrm{H})$ curves obtained in small external fields.

Taking into account the analysis of the ZFC-FC curves the $M(H)$ loops were fitted considering both small superparamagnetic and ferromagnetic contributions using an IGOR PRO software [20] and the typical functions to describe principal magnetic contributions and a grain size of nanoparticles [21,22]: $M(H)=M_{\mathrm{FM}}(H)+M_{\mathrm{SPM}}(H), D_{\mathrm{m}}=\alpha e^{\beta^{2} / 2}$, where $M_{\mathrm{FM}}(H)$ is the ferromagnetic 


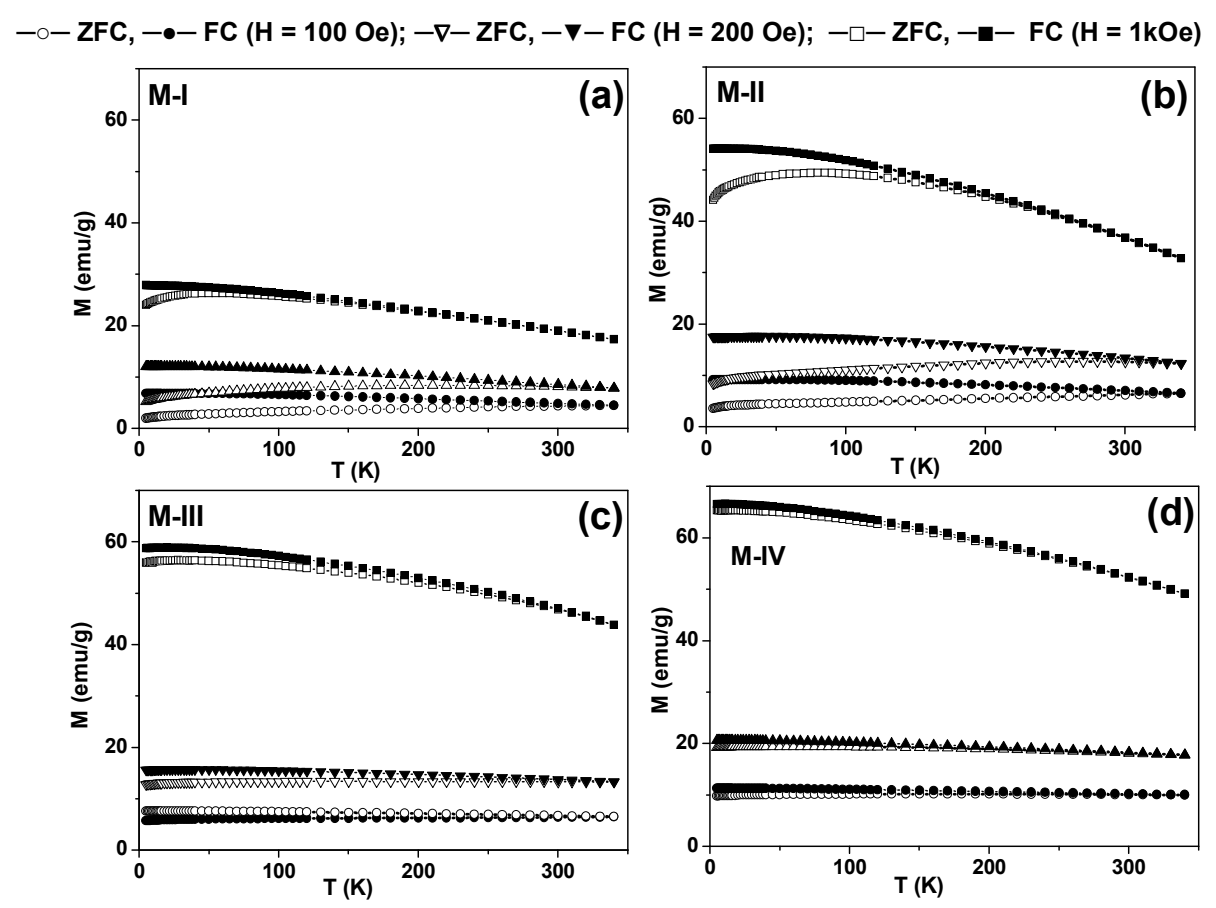

Fig. 6. Zero field cooling (ZFC) and field cooling (FC) curves for various values of an external applied field $H$ for M-I (a), M-II (b), M-III (c) and M-IV (d) $\mathrm{Ni}_{0.35} \mathrm{Cu}_{0.15} \mathrm{Zn}_{0.5} \mathrm{Fe}_{2} \mathrm{O}_{4}$ nanoparticles.
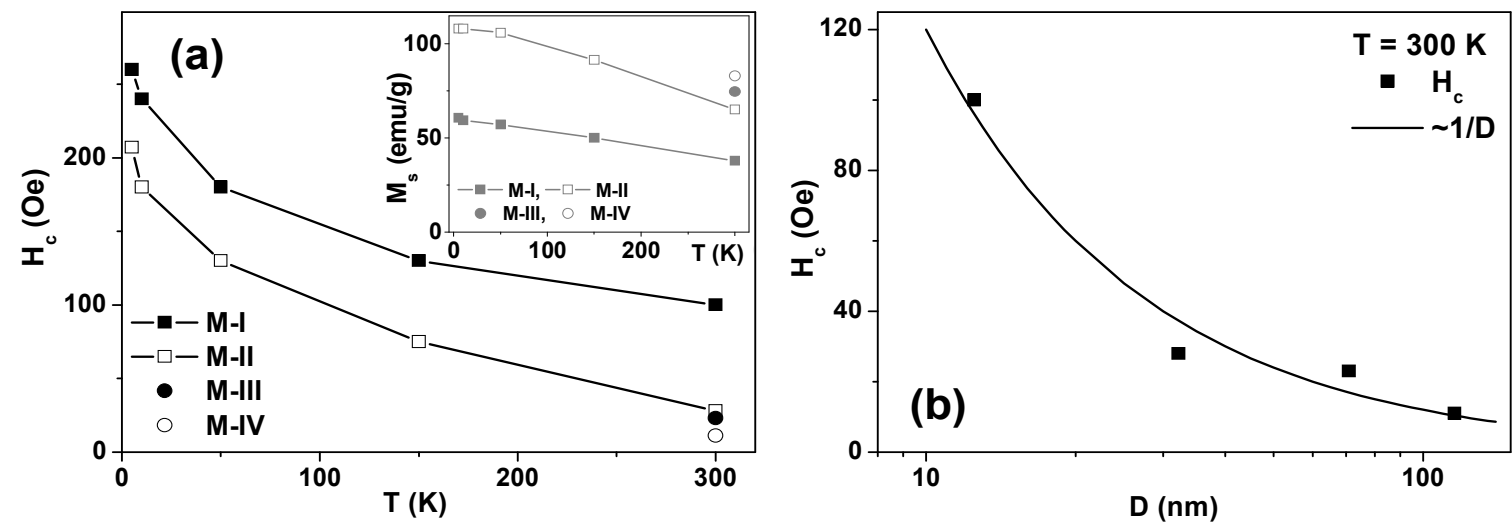

Fig. 7. Temperature dependence of the coercivity for M-I, M-II, M-III and M-IV samples (a); the insert shows the temperature dependence of the saturation magnetization. The dependence of room-temperature coercivity on the average size of $\mathrm{Ni}_{0.35} \mathrm{Cu}_{0.15} \mathrm{Zn}_{0.5} \mathrm{Fe}_{2} \mathrm{O}_{4}$ nanoparticles (b).

contribution and $M_{\mathrm{SPM}}(H)$ is the superparamagnetic contribution; $\alpha$ and $\beta$ are parameters included in the log-normal distribution of the grain sizes [23]. The example of the fits is shown in Fig. 8. Although the fit look fairly good (Fig. 8) the errors in the determination of the parameters were quite high and the values of the experimental errors increased very much with an increase of the temperature of the post preparation treatments.

Table 2 describes selected fitting parameters for some samples: $\beta$ is usually considered between 0.5 and $1.5[21,22]$. The difference between the grain size estimated from structural methods and magnetic measurements fitting shows usual tendency: for small nanoparticles $D_{\mathrm{m}}<D$ or $D_{\mathrm{TEM}}$. An increase of the difference with the increase of the grain size tells that the simple model becomes less appropriate for the magnetic system description. No reasonable fitting was found for M-III and MIV samples indicating that the state of the magnetic system becomes really complicated. 


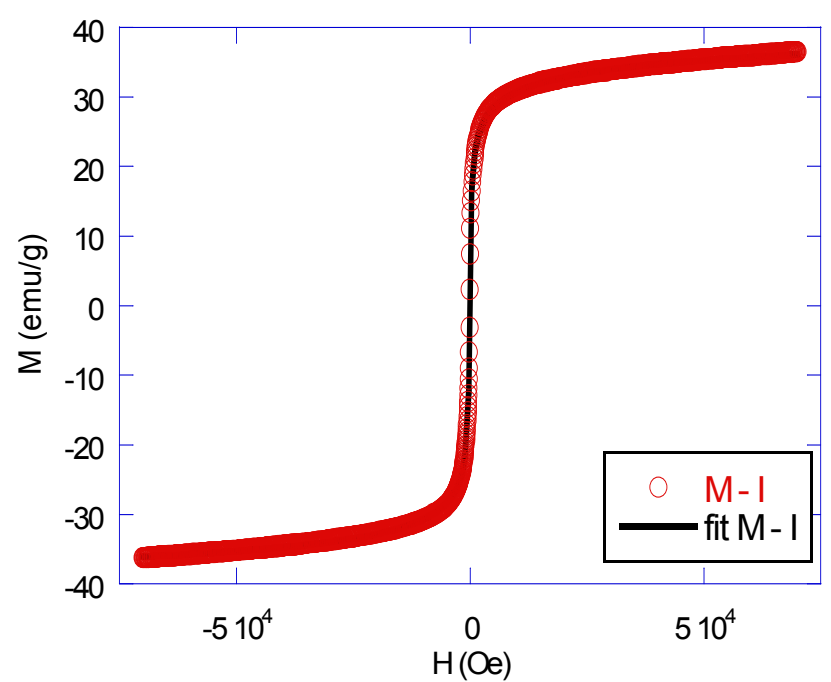

Fig. 8. Hysteresis loops measured at $300 \mathrm{~K}$ for the M-I $\left(\mathrm{Ni}_{0.35} \mathrm{Cu}_{0.15} \mathrm{Zn}_{0.5} \mathrm{Fe}_{2} \mathrm{O}_{4}\right)$ nanoparticles: experimental and IGOR PRO software fit [20].

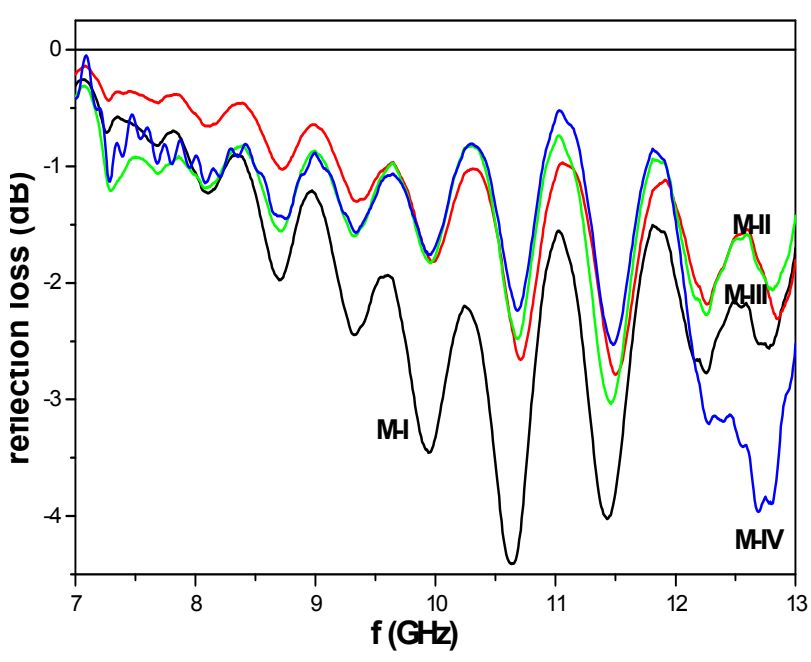

Fig. 9. Reflection loss dependency on the frequency for the powders of NiCuZn-epoxy ferrites.

Reflection losses $\left(R_{\mathrm{L}}\right)$ in ferrites are related to magnetic and dielectric behavior of these materials, to ferrite-composite ratio and sample thickness. Figure 9 shows the frequency dependence of the return loss for all the ferrite samples. In the X-band range a clear difference in microwave behavior of the obtained nanoparticles was observed. The M-I sample shows a maximum $R_{\mathrm{L}}$ of $4.5 \mathrm{~dB}$ at $10.6 \mathrm{GHz}$ while the M-IV sample shows a maximum $R_{\mathrm{L}}$ of $4.0 \mathrm{~dB}$ centered at $12.7 \mathrm{GHz}$ with broad absorption peak of $0.8 \mathrm{GHz}$ near to $3 \mathrm{~dB}$ in the range 12.1-12.9 GHz. As it was earlier reported for Ni-ferrites spin resonance frequency increases with particle size [24]. Thus, for low annealing temperatures when the particle size is still small only spin resonances are present. The domain wall resonances appear when the particle size reaches the single domain size. R.H. Kodama et al. [25] showed that the disordered surface spins of ferrite nanoparticles can additionally contribute to the microwave absorption. Although further studies with higher ferrite ratio/different thickness are necessary, the obtained results indicate that $\mathrm{Ni}_{0.35} \mathrm{Cu}_{0.15} \mathrm{Zn}_{0.5} \mathrm{Fe}_{2} \mathrm{O}_{4}$ ferrite/epoxy composite can be used as RAM.

Table. 2. Selected data for fitting of the $M(H)$ loops of M-I and M-II samples at room temperature. The size of the particle $D_{\mathrm{m}}$ was calculated from $\alpha$ and $\beta, D$ from X-ray, $D_{\text {TEM }}$ from TEM.

\begin{tabular}{|l|l|l|l|l|}
\hline Sample & fitting parameters & $D_{\mathrm{m}}$ & $D$ & $D_{\text {TEM }}$ \\
\hline M-I & $\begin{array}{l}\alpha=3.9167 \pm 0.222 ; \beta=0.80897 \pm 0.0661 \\
M_{\mathrm{S}}(\text { for SPM })=22.38 \pm 1.73 ; M_{\mathrm{s}}(\text { for FM) }=17.87 \pm 1.32\end{array}$ & $5.5 \mathrm{~nm}$ & $12.5 \mathrm{~nm}$ & $15-20 \mathrm{~nm}$ \\
\hline M-II & $\begin{array}{l}\alpha=5.7819 \pm 0.388 ; \beta=0.82987 \pm 0.0656 \\
M_{\mathrm{S}}(\text { for SPM })=45.92 \pm 3.03 ; M_{\mathrm{S}}(\text { for FM) }=22.70 \pm 2.42\end{array}$ & $8.2 \mathrm{~nm}$ & $32.2 \mathrm{~nm}$ & $15-20 \mathrm{~nm}$ \\
\hline
\end{tabular}

\section{Conclusions}

Ultrafine NiCuZn nanoparticles were prepared by the sol-gel self-combustion method. Their structural, magnetic, and microwave properties were studied as a function of the annealing temperature. The obtained materials are indeed uniform single cubic fcc $(\mathrm{Fd} 3 \mathrm{~m})$ phase spinels having typical $\mathrm{NiCuZnFe}$ phases. The grain size increases from $12 \mathrm{~nm}$ to $115 \mathrm{~nm}$ with increasing sintering temperature. For all the samples and temperatures the non-zero coercivity was observed indicating the presence of strong ferromagnetic contribution. Microwave absorption results show that in the X-band range M-I ferrite has a maximum $R_{\mathrm{L}}$ of $4.5 \mathrm{~dB}$ at $10.6 \mathrm{GHz}$ while sample M-IV has a maximum $R_{\mathrm{L}}$ of $4.0 \mathrm{~dB}$ at $12.7 \mathrm{GHz}$, i.e. M-I ferrite/epoxy composite can be used as RAM. 
This project was supported by UBACyT (I-011) and INTECIN (UBA-CONICET) and by the MAT2008-06542-C02-02_MAT) and PE08UN03 projects. Technical and human support provided by SGIker services of UPV-EHU is gratefully acknowledged. Special thanks to A. Larranaga, I. Orue and J. Alonso for excellent support.

\section{References}

[1] N. Popandian, A. Narayanasamy, C.N. et al.: Appl. Phys. Lett. 86 (19) (2005), p.192510.

[2] Zhao, Dong-Lin, Lv Qiang, Shen Zeng-Min: J. Alloys and Comp. Vol. 480 (2009), p. 634.

[3] T. Nakamura: J. Mag. Mag. Mater. Vol. 168 (1997), p. 285.

[4] J.J. Shroti, S.D. Kulkarni, et al: Mater. Chem. and Phys. Vol. 59 (1999), p. 1.

[5] N. Rezlescue, E. Rezlescue, C. Pasnicu, et al: J. Phys.:Condens. Matter Vol. 6 (1994), p. 5707.

[6] A.C. Razzitte, W.G. Fano, S.E. Jacobo: Physica B Vol. 354 (2004), p. 228.

[7] S.E. Jacobo, W.G. Fano, A.C. Razzitte: Physica B Vol 320/1-4 (2002), p. 257.

[8] J. Hu, M. Yan, W. Luo, J.M. Wu: Physica B Vol. 400 (2007), p. 119.

[9] J. Hu, M. Yan, W.Y. Zhang: Mater. Chem. Phys. Vol. 98 (2006), p. 459.

[10] H. Su, H. Zhang, X. Tang, Y. Jing: J. Mag. Mag. Mater. Vol. 302 (2006), p. 278.

[11] E. E. Sileo, R. Rotelo, S.E. Jacobo: Physica B, Vol. 320/1-4 (2002), p. 261.

[12] S. Zahi, M. Hashim, A.R. Daud: Mater. Lett. Vol. 60 (2006), p. 2803.

[13] Debye P, Scherrer P: Interference on Inordinate Orientated Particles in X-ray Light. III. Physikalische Zeitschrift Vol. 18 (1917), p.291.

[14] H.M. Rietveld.: J. Appl. Crystallogr. Vol. 2 (1969), p. 65.

[15] J. Rodriguez-Carvajal: Physica B, Vol. 192 (1993), p. 55.

[16] L. Yu, Sh. Cao, Y. Liu, et al: J. Magn. Magn. Mater. Vol. 301 (2006), p. 100.

[17] Hao-Ying Lu, Sheng-Yuan Chu, et al.: Journal of Crystal Growth Vol. 269 (2004), p. 385.

[18] W.C. Hsu, S.C. Chen, et al: Mater. Sci. Eng. B Vol. 111 (2004), p.142.

[19] J.C. Aphesteguy, S.E. Jacobo, N.N. Schegoleva, and G.V. Kurlyandskaya: J. Alloys and Comp. Vol. 495 (2010), p. 509.

[20] G.V. Kurlyandskaya, J. Cunanan, S.M. Bhagat, J.C. Aphesteguy, S.E. Jacobo: J. Phys. Chem. Solids Vol. 68 (2007), p. 1527.

[21] G.V. Kurlyandskaya, S.M. Bhagat, et al.: J. Appl. Phys. Vol. 99 (2006) p. 104308.

[22] Igor Pro (WaveMetrics, Lake Oswego, OR, USA).

[23] S. Li, B. Cui, F. Zhang, Y. Du, X. Jiang: J. Appl. Phys. Vol. 95 (11) (2004), p. 7420.

[24] S.E. Jacobo, J.C. Aphesteguy, R. Lopez Anton, N.N. Schegoleva, G.V. Kurlyandskaya: European Polymer Journal Vol. 43 (2007), p.1333.

[25] L. Rade and B. Westergren in: Mathematics Handbook for Science and Engineering, edited by Studentliteratur, (1995).

[26] T. Giannakopolou, L. Kompotiaiis, et al.: J. Mag. Mag. Mater. Vol. 246 (2002), p. 360.

[27] R.H. Kodama, A.E. Berkowitz: Phys. Rev. B Vol. 59 (1999), p. 632. 